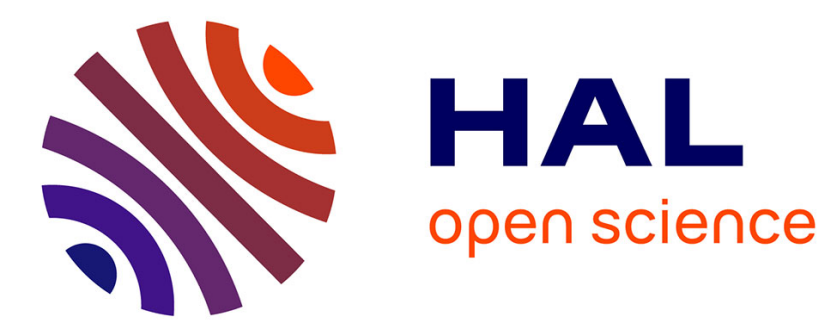

\title{
Practising childbirth activism: a politics of evidence
}

Madeleine Akrich, Maire Leane, Celia Roberts, João Arriscado Nunes

\section{To cite this version:}

Madeleine Akrich, Maire Leane, Celia Roberts, João Arriscado Nunes. Practising childbirth activism: a politics of evidence. 2012. halshs-00702075

\section{HAL Id: halshs-00702075 https://shs.hal.science/halshs-00702075}

Preprint submitted on 29 May 2012

HAL is a multi-disciplinary open access archive for the deposit and dissemination of scientific research documents, whether they are published or not. The documents may come from teaching and research institutions in France or abroad, or from public or private research centers.
L'archive ouverte pluridisciplinaire HAL, est destinée au dépôt et à la diffusion de documents scientifiques de niveau recherche, publiés ou non, émanant des établissements d'enseignement et de recherche français ou étrangers, des laboratoires publics ou privés. 


\title{
$N^{\circ} 023$
}

2012

Practising childbirth activism: a politics of evidence

\author{
Madeleine Akrich \\ Centre de Sociologie de l'Innovation \\ Mines ParisTech \\ madeleine.akrich(a)mines-paristech.fr \\ Maire Leane \\ University College Cork \\ m.leane(a)ucc.ie \\ Celia Roberts \\ Lancaster University \\ celia.roberts(a)lancaster.ac.uk \\ and \\ João Arriscado Nunes \\ Centre for Social Studies \\ University of Coimbra \\ jan(a)ces.uc.pt \\ Centre de Sociologie de L'INNOVAtion \\ MINES PARISTECH / CNRS UMR 7185 \\ 60 Boulevard Saint-Michel \\ 75272 Paris cedex 06 FRANCE \\ http://www.csi.mines-paristech.fr/
}


PAPIERS DE RECHERCHE DU CSI

Cette collection a pour but de rendre aisément disponible un ensemble de documents de travail et autres matériaux de discussion issus des recherches menées au CSI (CENTRE DE SOCIOLOGIE DE L'INNOVATION).

Tous les droits afférant aux textes diffusés dans cette collection appartiennent aux auteurs.

Des versions ultérieures des papiers diffusés dans cette collection sont susceptibles de faire l'objet d'une publication. Veuillez consulter la base bibliographique des travaux du CSI pour obtenir la référence exacte d'une éventuelle version publiée.

\title{
CSI WORKING PAPERS SERIES
}

The aim of this collection is to make easily available a set of working papers and other materials for discussion produced at the CSI (CENTRE DE SOCIOLOGIE DE

$$
\text { L'INNOVATION). }
$$

The copyright of the work made available within this series remains with the authors.

Further versions of these working papers may have been submitted for publication. Please check the bibliographic database of the CSI to obtain exact references of possible published versions.

\author{
CentRe de Sociologie de l'INNOVATION \\ MINES PARISTECH / CNRS UMR 7185 \\ 60 Boulevard Saint-Michel \\ 75272 Paris cedex 06 FRANCE \\ http://www.csi.mines-paristech.fr/
}




\title{
Practising Childbirth Activism: a Politics of Evidence
}

\author{
Madeleine Akrich, Maire Leane, Celia Roberts, João Arriscado Nunes
}

\begin{abstract}
The literature on childbirth organisations focuses on their critical positioning towards medical definitions/practices of birth, their efforts to promote 'natural'/'normal' birth, their espousal of a rhetoric of choice and their relationships to feminist activism.
\end{abstract}

However it says little about the practices through which these organisations seek to achieve their aims. Based upon a comparative study in the UK, Ireland, Portugal and France, we show that in all four organisations, knowledge related activities are central to their activism. Four configurations can be distinguished based on the nature of the evidence underpinning the activism: Irish activism drew extensively on surveys on women's experiences; UK activism focused on the collection of statistical evidence on medical practices; scientific evidence was put centre stage by the French childbirth organization whereas the young Portuguese movement harnessed international authoritative evidence to support its change agenda.

Through these activities, the organizations contributed to the production of knowledge, established or expanded discursive spaces and identified new fields of actions. The connections between evidence based activism and the re-shaping of organisational objectives and agendas are made visible as well as the constitutive role of these organisations in naming and framing issues relating to childbirth as distinct from merely opposing medicalization. 


\section{Keywords}

Patients' organisations, Childirth, France, Portugal, UK, Ireland, Evidence-based medicine, Statistics

\section{Introduction}

What do childbirth organisations in Western countries do? A review of existing literature reveals a degree of similarity in their causes which cluster around four key goals: (1) problematising medical/technical intervention in birth; (2) promoting "natural"/'normal" or "mother friendly" birth; (3) demanding birth practices and settings that are attentive to and respectful of the desires of birthing women and their families and (4) championing women's right to make informed choices about type and place of birth. The literature discusses contested relationships between birth activist groups and various feminisms (Reiger, 1999, 2000; Beckett, 2005), focusing notably on tensions generated by articulations of normality and choice in childbirth politics.

The notion of choice for example, was deployed by first wave feminist birth activists advocating women's right to pharmacological pain relief, but also underpinned calls for alternatives to medicalised hospital birth during second wave feminism; in contemporary contexts of postmodern and third wave feminism, it is used to articulate the right to choose elective Cesarean section (Beckett, 2005). This championing of self determination and choice, which comes with the recognition of differences between women, is considered problematic by some commentators who see it as promoting a form of individualised relativism unable to provide a basis for group activism for change (Tong, 2007; Gillis \& Munford, 2004, Thoma, 2009; Reiger \& Dempsey, 2006). Some critics view the imperative to choose as a new constraint (Samerski, 2009), while others challenge the assumption that women can actually 
make choices and exert control in relation to childbirth given the asymmetry of knowledge, experience and authority between women and professionals (Crossley, 2007; Hensley Owens, 2008; Halfon, 2010; Shaw, 2007). Donovan (2006) goes a step further and argues that having to make choices about pregnancy and birth ultimately puts medicine at the heart of women's experiences and is contrary to making these processes "natural" and "normal".

Attempts to elaborate childbirth policy have proved similarly contentious. Discussions of concepts such as "natural birth", "normal birth", "good birth" etc. feature frequently in birth activist literature. "Natural" childbirth in the 1930s was birth without medication or obstetric intervention where women, educated about their bodies and labouring in supportive environments, would draw on their innate capacities to birth (Dick-Read, 1956). This understanding of "natural" birth was promoted by childbirth organisations in the late 1950s and early 1960s in the UK and the US to challenge the scientification of motherhood which was disempowering women to the benefit of doctors (Weiner, 1994). More recent feminist theorising argues that such politics assume a universal female essence and an essentialised understanding of the female body as outside of history and culture, which if left to its own devices will perform a natural birth (Murphy-Lawless, 1998; Halfon, 2010: 71). Other critics assert that women define normal birth in highly individualised ways (Hunter, 2007; Downe, 2004). Notwithstanding these limitations, Darra (2009: 300) notes that in contemporary British childbirth policy and practice "normalisation [of birth] is...the current driving force". She highlights that the desirability of "normal" birth and guidelines to promote its achievement are widely espoused and integrated into international and national guidelines for the governance of health (WHO, 1996; NICE, 2007), into the professional self-definition of many midwifery groups at international and national levels and into the objectives of a range of lay childbirth organisations. 
This literature provides useful insights into debates and conflicts within childbirth politics; it highlights that the concepts underpinning the aims of most childbirth organisations (Goer, 2004), while lacking definitional consistency, are widely deployed, reflecting historical developments in maternity practices and feminist theorising. In contrast to this focus on concepts and philosophies, this paper, based on a comparative study of four birth activist organisations in the UK, Ireland, Portugal and France, focuses on each organisation's activities and practices. We show that each organisation engages in a range of activities involving the production, elaboration, re-shaping or translation of knowledge and argue that "evidential work" is a major characteristic of childbirth activism.

The involvement of patient organisations in knowledge work is well documented (Epstein, 1996; Barbot, 2006; Rabeharisoa \& Callon, 2002; Rabeharisoa, 2003; Jasanoff, 2005). In their overview of UK health consumer movements including childbirth organisations, Allsop and colleagues (2004) highlight the role of lay expertise as constitutive of the groups and as a key aspect of their contribution to policy making; moreover they underline the work performed by these organisations in building knowledge and expertise. However our detailed analysis of the activities of childbirth organisations reveals engagement in knowledge activities that go beyond the production and use of knowledge as a form of cultural capital or political leverage. What is made visible in our research are the ways in which the organisations reflexively engage with the knowledge produced and the knowledge practices engaged in, resulting in a dynamic process through which the activities and potentially the missions and objectives of the organisations themselves are shaped and reshaped. What we investigate here is how these organisations build "matters of concern" which, as Bruno Latour (2005: 4) notes, are much more essential to politics than "sets of values, opinions, attitudes or principles".

Significantly while knowledge practices and reflexive engagement with these are central to all of the organisations, articulations between knowledge activities and activism differ between 
them. To explore these differences we concentrate on some key actions in the recent past (2000-2011). Four configurations can be distinguished based on the nature of the evidence underpinning the activism. In the British example, we describe the way in which statistics were deployed in elaborating a consensus document on "normal birth". In the French case, the commissioning of scientific evidence and its role in the elaboration of practice guidelines is highlighted. Experiential evidence collected through surveys and the use of this evidence to refine organisational strategy and elaborate causes is explored in the Irish situation. While in the Portuguese case the harnessing of international authoritative evidence to support a change agenda is examined.

The remainder of this article unfolds in three parts. The next section provides a brief outline of the four organisations involved in the research, with particular emphasis on the discursive deployments of the concepts of "natural", "normal" and "choice" in each organisation's selfdescription and mission statement. This is followed by an examination of the organisations' key knowledge activities and a final discussion exploring the implications of the observed centrality of knowledge-based activities for understandings of childbirth activism.

\section{Childbirth Organisations in France, Ireland, UK and Portugal as pluralist and} evolving organisations

The organisations we studied are: the National Childbirth Trust (now NCT, UK), the Association for the Improvement of Maternity Services, Ireland (AIMSI), the Collectif interassociatif pour la naissance (CIANE, France) and the Associação Portuguesa Pela Humanização do Parto (HUMPAR, Portugal) Our studies were conducted between 2009 and 2012 using a common methodology involving analysis of a range of data sources including: the organisations' websites and online forums; reports, leaflets and documents issued by the 
organisations; interviews with members; and observations made during meetings, events and classes held by an organisation.

The four organisations differ in many aspects; date of creation, size, membership, type of activities. The sharpest contrast is between the NCT - an old and large organisation which is also a service provider (antenatal classes) - and the other three younger and smaller organisations, which are primarily committed to activism with two of them also having a support dimension.

\begin{tabular}{|c|c|c|c|c|}
\hline & NCT (UK) & AIMS Ireland & CIANE (France) & Humpar (Portugal) \\
\hline $\begin{array}{l}\text { Date of } \\
\text { creation }\end{array}$ & 1956 & $\begin{array}{l}2007 \text { (re-creation of } \\
\text { an organisation which } \\
\text { has been active from } \\
1979 \text { to late } 90 \text { s) }\end{array}$ & 2003 & 2006 \\
\hline $\begin{array}{l}\text { Approximate } \\
\text { membership } \\
\text { (individuals) }\end{array}$ & 100000 & 120 & $\begin{array}{l}40 \text { childbirth } \\
\text { organisations }\end{array}$ & 700 \\
\hline $\begin{array}{l}\text { Type of } \\
\text { membership }\end{array}$ & $\begin{array}{l}\text { Users } \\
\text { (+ a professional } \\
\text { staff alongside } \\
\text { volunteers) }\end{array}$ & Users & $\begin{array}{l}\text { Users who are all } \\
\text { volunteers in the } \\
\text { member organisations }\end{array}$ & $\begin{array}{l}\text { Users and medical } \\
\text { professionals } \\
\text { (obstetric nurses, } \\
\text { doulas) }\end{array}$ \\
\hline Activities & $\begin{array}{l}\text { - } \text { Education and } \\
\text { support } \\
\text { - Campaigning } \\
\text { - Involvement in } \\
\text { policy making } \\
\text { - Commercial } \\
\text { - } \text { activities } \\
\text { Research- } \\
\text { related activities }\end{array}$ & $\begin{array}{l}\text { - Support } \\
\text { - Information } \\
\text { - Campaigning } \\
\text { - Undertaking } \\
\text { research }\end{array}$ & $\begin{array}{l}\text { - } \text { Campaigning } \\
\text { - Involvement in } \\
\text { policy making } \\
\text { - Involvement into } \\
\text { the writing of } \\
\text { guidelines } \\
\text { - Research-related } \\
\text { activities }\end{array}$ & $\begin{array}{l}\text { - } \text { Support } \\
\text { - } \text { Campaigning } \\
\text { - Involvement in } \\
\text { policy making }\end{array}$ \\
\hline $\begin{array}{l}\text { Mission } \\
\text { statement }\end{array}$ & $\begin{array}{l}\text { - Information and } \\
\text { support } \\
\text { - To improve } \\
\text { maternity care } \\
\text { - Informed } \\
\text { choices for } \\
\text { parents }\end{array}$ & $\begin{array}{l}\text { - Normal birth and } \\
\text { mother-friendly } \\
\text { birth practices } \\
\text { - Supported by } \\
\text { evidence-based } \\
\text { research and } \\
\text { - International best } \\
\text { practice } \\
\text { - Informed choices } \\
\text { for parents }\end{array}$ & $\begin{array}{l}\text { - High quality care } \\
\text { supported by } \\
\text { evidence-based } \\
\text { medicine } \\
\text { - Personalised and } \\
\text { respectful care } \\
\text { - Diversification (free } \\
\text { standing birth } \\
\text { centres, homebirth) } \\
\text { - Informed choices } \\
\text { for parents }\end{array}$ & $\begin{array}{l}\text { - Humanisation of } \\
\text { birth } \\
\text { - } \text { Childbirth as a } \\
\text { normal } \\
\text { physiological event } \\
\text { - } \text { Legalisation of } \\
\text { homebirth } \\
\text { - Reduction of } \\
\text { medical procedures } \\
\text { (WHO } \\
\text { recommendations) }\end{array}$ \\
\hline
\end{tabular}


The table above summarises the organisations' mission statements as they appear on their websites. From this we observe significant overlap with the birth activism discussed in the existing literature, referring to "normal birth", "physiological birth", "humanised birth" and "choice". We also note the use of terms such as "evidence-based research", "international best practice" and "WHO recommendations", terms which bring the idea of knowledge as a normative reference to the fore, an idea which has not been extensively highlighted in the literature with the exception of the writings of some birth activists (Beech, 2011; Goer, 2003, 2004; Phan, 2010; Zwelling, 2002), and those of a few scholars who evoke it in passing (Beckett \& Hoffman, 2005; Graham, 1998; Williamson, 2008).

This multiplicity of normative principles evoked or employed by the organisations is significant but unsurprising in light of the tensions, contradictions and conflicts between such principles identified in the literature above. In the cases we studied, this engagement with a multiplicity of principles constitutes a form of internal "pluralism" which appears to result from the way the organisations have formed and evolved. For example, the NCT has shifted from an original focus on "natural childbirth" to the promotion of "informed choice" and the development of concepts such as "good birth" or "normal birth". The CIANE brought together about 30 organisations, each bringing its own historical background and aspirations including: promotion of homebirth with an emphasis on childbirth as a natural/physiological process; respect for the rights of the parents to make their own choices, whatever their preference; women's self-determination; and reference to EBM. The mission statements of the organisations are the products of an evolving "sedimentation" and "aggregation" process which is always in flux. As such the mission statements do not provide a set of static principles from which actions flow. To understand actions, then, we need to observe organisations in practice. The following sections describe a recent activity of each organisation observed during the course of our study. 


\section{Making normal birth an operative category: statistical evidence about practices}

\section{as a coordination device in the UK}

The NCT has always had an interest in evidence: in its earliest manifestation, it circulated Grantly Dick-Read's (1956) educational film "Childbirth Without Fear", documenting women's experiences of his techniques of "natural" birth. From the mid 1970s, the organisation became increasingly committed to producing their own evidence, commissioning research from then NCT member Sheila Kitzinger amongst others about women's experiences of medicalised birth (Kitzinger, 1975; 1981; 1987). As well as producing their own "in house" (usually survey-based) reports and commissioning other research, the organisation collects, circulates and engages with published data, teaching members critical reading skills and conducting study groups on particular topics. A relatively small number of people are involved in such activities, most notably the Head of Research and Information, but they are highly energetic and productive, engaged not only in report-writing and the preparation of "evidence-based" NCT statements but in publishing in leading medical journals (Johannson and Newburn, 2001; 2002). The NCT's attention to evidence in the current setting, then, builds on a long history of making and intervening in knowledge about birth. Today, the NCT harnesses specific forms of expertise in garnering and producing knowledge but is strategic and selective in its use of data: knowledge for the NCT is a political project not an academic one, closely tied to policy development and attempts to influence practice at every level (from individual birth plans and experiences to national clinical practice guidelines).

The NCT has been highly successful in achieving status within policy organisations. In 2000, it was involved in establishing the Maternity Care Working Party (MCWP), an expert advisory group addressing the public health implications of the rising caesarean rate (MCWP, 2007: 1) and providing evidence to the All-Party Parliamentary Group on Maternity 
(APPGM), "a cross-party group of MPs and Peers with an interest in the maternity services... [that] raises awareness of the important part that maternity provision has to play in improving women and babies' health.” In 2007, chaired by the NCT, this group published a consensus statement on normal birth that has become a model across Europe.

\section{Developing the consensus statement: producing knowledge and expertise}

The formal process of developing the consensus statement began in November 1999 with a national conference organised by the NCT, The Royal College of Midwives and The Royal College of Obstetricians and Gynaecologists, entitled 'The Rising Caesarean Rate - a public health issue". The proceedings of the conference included a statement from the MCWP about normal birth, claiming that "most women would prefer to give birth normally, provided that a normal birth is considered safe for them and their baby." (MCPW, quoted in the Guardian, 24 Nov. 1999) Over the next eight years, the NCT, particularly their Head of Research and Information, Mary Newburn, led a drafting and redrafting process culiminating in the consensus statement However it was a small number of childbirth activists (Beverly Beech, Soo Downe and Miranda Dodwell), two of whom were not members of the NCT, who were arguably the key architects of the normal birth agenda, feeding statistical and conceptual knowledge into the MCWP's activities and strongly influencing the NCT's position on these matters.

In 1997 the World Health Organisation had defined normal birth as:

Spontaneous in onset, low-risk at the start of labour and remaining so throughout labour and delivery. The infant is born spontaneously in the vertex position between 37 and 42 completed weeks of pregnancy. After birth mother and baby are in good condition. (WHO 1997) 
In the same year, Beverley Beech of the Association of Improvements in Maternity Services (AIMS) argued that the WHO definition included a variety of often unnecessary medical interventions and that routine hospitalisation meant that most practitioners did not understand normal birth (Beech, 1997). Beech argued that hospital case notes should record interventions and if procedures such as artificial rupture of membranes, induction of labour, acceleration of labour, epidural anaesthesia or episiotomy were carried out, the birth should be recorded as "technological" rather than "normal".

Reacting to this article, Soo Downe (now Professor of Midwifery Studies, University of Central Lancashire) proposed joint research on "normal birth", conducting a retrospective analysis of case notes in five consultant units (Downe et al, 2001). Using the 1997 AIMS criteria, they found that barely one in four women had a normal birth, despite the fact that the study included women who had pain-relieving drugs, electronic fetal heart monitoring and syntometrine for the third stage of labour. Downe et al queried both the definition of normal as "without intervention" and as "the most common experience of women" (the latter would mean that an obstetric birth became "normal"). Discussing the variation in definitions of normality used in reports from official bodies, they concluded both that many births recorded as "normal" involve medical interventions and that a great majority of women experience some kind of intervention during labour. Downe and Beech were both MCWP members and their work contributed directly to developing the consensus statement.

Perhaps the most significant contribution, however, was the publication by BirthChoice UK of statistics on normal birth. Established by NCT antenatal teacher Miranda Dodwell in 2001, this organisation published 1998 statistics (the most recent available at the time) gleaned from the Department of Health. Dodwell described this in an interview with us: 
I phoned up this person [indicated on a document] ... and said "Can I have a copy of this?" They said, "Sure, we'll send it to you in the post". And it arrived and it was the caesarean rate from every hospital in the country! And I just went, "I never knew this existed!” Nobody I talked to knew it existed, and it was obviously put into some dusty cupboard at the Department of Health. (interview, 2010)

These statistics were based on records of "normal delivery rates" but the information was limited to where interventions had taken place. It was not possible, then, to reconstruct birth cases and to calculate the rates of normal birth from the statistics using Beech's definition.

Dodwell explains how this work developed over the following decade, becoming critical to defining "normal birth":

We were using statistics on interventions and I became aware of the normal birth agenda. It really came from Soo Downe and AIMS - around 2003. (...) The basis of that definition was what we could get from the Department of Health: so the DoH had inductions but they didn't have any data about augmentation, so we couldn't exclude that from normal birth; they had data about epidurals; they didn't have anything about pethidine. So we were basically limited by what they could produce. So that was our definition, it was as "normal" as we could get given what the Department of Health collected and we put that on our website. (...) We originally called it the 'BirthChoiceUK Definition of Normal Birth.' (...) It's now in Europe as well, Peristat Report for Europe ... they reference BirthChoice UK as being the original. (interview 2010)

Dodwell quickly became seen as having expertise in maternity statistics and was invited to join various influential policy groups. She describes the power of "having numbers": 
I think having numbers allowed that shift to think about how you normalise birth. Soo Downe and AIMS were already looking at it, and I think beginning to have routine data on normal birth also helped give you something real, it wasn't some nebulous concept any more, it was something you could measure and I think that was really important. (interview, 2010)

The promotion of normal birth in the consensus statement circulates both a technical definition of and statistical information about normal birth. These emerged out of, and were motivated by, reflection on women's experiences of childbirth by women who become key actors in birth politics and MCWP members. Achieving this definition has had important political results: although debate continues, the document allows the NCT to "move on" (or back) to other areas of action, trying for example, to pursue the enactment of practices that might mean more women experience a "normal birth".

The consensus statement renders "normal birth" an operative notion. The definition of "normal birth" accomplished here is neither the one that has been proposed by WHO nor AIMS' definition but is determined by rather pragmatic arguments, relating to the possibility of producing statistics. Fitting the existing set of data made available to the public through BirthChoiceUK's website, the definition also creates a common reference for discussions between consumers and professionals.

Because it is measurable, the "normal birth" notion can also be translated into a set of clear and defined objectives and the fulfilment (or not) of these objectives can be traced. The definition offers a device through which to evaluate the quality of care: in 2010, for example, the NCT produced a report entitled "Normal birth as a measure of the quality of care: evidence on safety, effectiveness and women's experiences" (Dodwell \& Newburn 2010). 
Work on evidence has played a major role in the NCT's (and AIMS') activism in the first decade of 21 st century. It resulted in a significant shift in the definition of its normative ambition: the "normal birth" notion does not refer anymore to some kind of spontaneous process in which there should be no medical intervention nor to the mother's viewpoint (a "good enough" birth, (Darra, 2009)) but to a process articulated through the absence of particular forms of medical intervention. Of course, this does not mean that competing normative orientations are definitively out of the game. The statement operates as a frontier delimitating a space of consensus from a space of dissensus, groups such as Birth Trauma or electivecesarean.com vocally disagree with it and make visible the tension that it creates both with notions of a "good" birth as seen from the mother's viewpoint and with the principle of "consumer choice". Other organisations, such as AIMS, also view the consensus statement as a tool for progress that does not and should not preclude the advent of "more advanced" practices (Beech, 2008).

\section{Producing evidence \& defining causes: putting surveys at the core of Irish} activism

From its inception in 2007 AIMSI has distanced itself from a 70s version of birth activism “..earthy, hippy you know... this natural birth stuff” and put knowledge at the core of their activities: "Now we push evidence-based, that is our thing, evidence-based, evidence-based, evidence-based" (interview with founding member, 2010). One of their first initiatives was a survey entitled What Matters To You 2007. Addressing potential respondents on its website, AIMSI articulated a clear rationale for the survey describing it as "...an invaluable tool for us to evaluate what issues are important to you and how they need to be tackled. " The survey was designed to systematically collect the experiences and views of consumers of Irish maternity services and was consistent with AIMSI' self-description as a "consumer-led" 
organisation. The core concerns identified in the 2007 survey informed three subsequent surveys undertaken by the organisation: Availability of Information and Consent (2008); "Rooming-In" in Irish Maternity Hospitals (2008); and Care at a Time of Loss: AIMSI Pregnancy Loss Survey (2009). The surveys provide information on numerous aspects of maternity provision including: the extent and nature of women's engagement with medical/clinical procedures and personnel during labour; the physical and infrastructural conditions in maternity units; the management and organisational practices in the units; information giving and consent during labour. Data on the emotional, psychological and physical impact of specific practices and conditions are also provided. In 2010, AIMSI ran another generic survey, What Matters to You: A Maternity Care Experience Survey, to reorient itself to key concerns among maternity service users. This ongoing surveying of consumers represents a strong, deliberate and continuous link between the production of knowledge and the definition of causes.

The simultaneous role played by surveys in defining causes and establishing a legitimate organisational identity was acknowledged by a former committee member who observed:

We always had that piece in there about conducting our own research in order to support women... you know to kind of systematise what people were telling us and give it more clout I suppose. (interview with committee member 2010)

The surveys also provided a mechanism for holding members' differing ideological positions in productive tension. As a former committee member noted “...we didn't have a shared ideology... we had a chat about feminism at one point... I could say I approached it as a feminist. I know other people could but other people didn't... it was just unresolved." However, AIMSI' public identification as a consumer advocacy group and its grounding of campaign issues in the concerns raised through the surveys, avoided the need for members to 
hold a shared ideological position. The knowledge produced through the surveys was used by AIMSI to (1) legitimate its representative role as an advocate for Irish maternity service consumers; (2) delineate its spheres of actions; (3) give empirical credibility to its claims and (4) stabilise diverse member ideologies.

\section{Turning matters of fact into matters of concern}

The surveys allowed AIMSI to promote specific concerns as public and political issues, i.e. to "highlight issues ... [and] bring them to the table" as a former committee member put it. For instance, evidence from the What Women Want Survey (2007) was cited by the organisation in a meeting with the Irish Minister for Health in highlighting the need for a nationwide extension of homebirth and Domino maternity services (midwife led services). The survey evidence also identified new fields of action for AIMSI and underpinned further knowledge related initiatives. For example, difficulties in accessing comprehensive information on the benefits and risks of a range of maternity related procedures revealed in the Availability of Information and Consent survey (2008) prompted AIMSI to produce the Healthy Birth Directory for the West of Ireland (2011. Knowledge from that survey also informed the launch of a campaign highlighting the inadequacy of consent procedures in Irish maternity units. This campaign included a call for an independent review of consent related practices and the organisation of a public seminar in 2010 entitled "Informed Consent in Maternity Care: Perspectives from Ireland \& the UK".

The dissemination of the survey data to professional, media and public audiences further contributed to the opening up of discursive fields within which maternity issues receive attention. The knowledge produced by the surveys has become part of the epistemic repertoire of other maternity support groups and of some midwives (AIMS Ireland, 2007). However those involved in the management and governance of maternity units have, for the most part, 
failed to publically acknowledge the surveys. A notable exception was the Care at a Time of Loss: AIMSI Pregnancy Loss Survey (2009) which generated a response from managers in a small number of maternity units, some of whom contacted AIMSI for recommendations on how to address the issues raised. Thus while it can be argued that the surveys "re-conceives the nature and boundaries of expertise" (Epstein 2008: 502), their limited impact on maternity care practices, and the failure to engage obstetricians, points to the very real challenges of establishing new ways of knowing (Hausman, 2005) within existing health governance structures.

\section{Reshaping epistemological boundaries}

The data produced in these surveys is empirical, evaluative and experiential. Both quantitative and qualitative approaches are employed and reports provide statistics alongside individual testimonies. While the surveys lack statistical power (they are based on self-selecting samples of women), their richness renders them powerful devices capable of adjustment for various purposes and audiences.

In deploying the knowledge produced through the surveys, AIMSI are not contesting medical knowledge in and of itself. They frequently invoke credentialised knowledge particularly relating to evidence-based practice and identify obstetric compliance with such knowledge as part of the solution to the problems identified in the surveys. As such, the survey knowledge is used to question the authority of doctors rather than to argue for a fundamental demedicalisation of maternity care. By translating localised knowledge about the micro techniques of power experienced by women in Irish maternity units through the language of international knowledge about evidence based practice, AIMSI hopes to mount a challenge to prevailing practices, a strategy that is acknowledged in the conclusion of its most recent survey: 
Finally, a greater challenge which can be seen to underpin the concerns raised by women in this survey, is to adopt and nurture a culture where evidence-based practice and the support of normal birth underpins every aspect of care. (What Matters to You: A Maternity Care Experience Survey AIMSI, 2010).

The surveys play a crucial role in structuring AIMSI activities and in constructing its network of influence. The knowledge produced legitimates AIMSI as a "consumer/users" representative and as an actor with moral and cognitive authority. This authority is strengthened by combining knowledge gathered through surveys with other types of knowledge based on evidence-based medicine and/or international guidelines. As such AIMSI activists are not simply sitting on the edge of the medical world waiting for professionals to respond to their preoccupations and to find solutions, but are taking the initiative to make propositions that articulate women's wishes in relation to obstetrics. Moreover, because the numbers and figures they produce are illuminated by testimonies, they maintain the personal and situated character of women's experience while creating resonance with and deriving strength from international analyses. The specifics of the Irish case are made visible but are viewed against the backdrop of a global situation.

\section{From scientific evidence to matters of concern: CIANE's participation in} producing French guidelines

The CIANE is a coalition of "user" organisations concerned with issues related to pregnancy and childbirth. It incorporates a variety of organisations: local community-based groups, large generalist organisations concerned with topics such as caesarean section, postnatal depression or breastfeeding and groups that had emerged from Internet mailing lists. This diversity allows the CIANE to combine political activism, field experience, a culture of sound debate and a certain mastery of specialised literature that provide them with a form of "interactional 
expertise" (Collins and Evans, 2002: 254). People who have long been active on mailing lists are accustomed to discussions that cut across exchanges of personal experiences and analyses of texts produced outside the group such as news articles, scientific papers and position papers: they are proficient in connecting individual experience, formalised knowledge and political arguments. More traditional organisations, turned towards parents seeking answers to questions, bring an additional expertise based upon daily contact with "ordinary" people. Entanglements between experiential knowledge and formalised knowledge, or between lay knowledge and expertise, have been at the heart of the CIANE since its creation. (Akrich, 2010)

The CIANE was established in 2003, in a context where citizen involvement in health policy was facilitated: a 2002 Act had introduced an obligation for all committees concerned with health care issues (in ministries, health agencies, hospital boards, etc.) to include representation of users of health care services. It is thus not surprising that the CIANE's has been devoted to participating in different health bodies, such as CNN (National Childbirth Committee), HAS (High Authority on Health, in charge of elaborating guidelines for clinical practice and evaluating guidelines elaborated by professional societies) or FFRSP (French Federation of Perinatal Health Networks). On its website, the CIANE also distinguishes five other activities: participating in professional and public conferences, writing and publishing papers (including in medical journals), contributing to public debate through conference organisation, establishing a partnership with two professional journals, circulating press releases and sending open letters to key players in order to raise awareness on specific issues. The CIANE thus invests most of its effort in producing and circulating knowledge. This orientation towards knowledge activities has been "theorised" in a series of three articles authored by a CIANE activist and published in a medical journal. In this series entitled "How perinatal care users call into question professional medical practice”, Phan (2010) argues that 
new kinds of mobilisation recently developed by maternity services users combine a challenging of professional practice with a critical analysis of scientific data made available by the development of the internet: she concludes that even if medical decision should not be based on science only and should take into consideration the practitioners' experience and individual preferences, the discussion on evidence allows to set up a productive dialogue with professionals.

Since its creation, the CIANE has participated in elaborating and/or evaluating more than 12 professional guidelines on varied topics. They have succeeded in influencing the HAS work program - a program which is based on requests from outside parties, professionals from the field, the state authorities and users. To this end, the CIANE carefully prepared such requests, requiring a highly formalised process and the mobilisation of scientific literature in order to build a convincing argument. Preparing requests has for many years been the CIANE's privileged mode of operative expression in policy development. The expertise of one of its member organisations has been decisive in this regard. The AFAR (Alliance francophone pour l'accouchement respecté) was founded by a few participants of the internet discussion list on childbirth who thought that the best strategy for changing childbirth care was to challenge what the professionals claim to be the source of their authority, namely science. They set up a public bibliographical database comprising more than 2,300 scientific references with abstracts and comments in order to help activists and individuals to question the "evidence" put forward by professionals who tended to impose medical interventions.

Drawing on AFAR's expertise, the CIANE has produced a number of requests on topics such as episiotomy, fundal pressure, induced labour and planned caesarean sections, which are all interventions that have more or less become routine in France. For a request on prenatal screening for Down syndrome, they joined forces with other actors, who also believed that the gap between international and French practices was resulting in a much higher rate of 
amniocentesis, a practice which contributes to a higher rate of miscarriage. In 2011 , they submitted a request on the calculation of due date, motivated by the influence which due date wields in the determination of the date after which an induction will be proposed/imposed. As can be observed from these examples, the topics addressed in requests clearly reflect issues of direct concern to pregnant women.

\section{Weaving different forms of expertise together: the episiotomy case}

Episiotomy was a recurring theme on the internet discussion list and was the first topic investigated by the AFAR shortly after its creation in 2003. In autumn 2004, drawing on the AFAR's work, the CIANE suggested episiotomy as a theme for the development of clinical practice recommendations. The National College of French Gynaecologists and Obstetricians (CNGOF) decided to adopt this initiative and make it its own, developing recommendations in 2005 and then consulting the CIANE.

The CIANE formed a work group and produced a proposal on these recommendations. The CNGOF text was almost exclusively technical, based on medical literature, and concluded briefly with a number of very general policy recommendations. Conversely, in addition to medical literature, the CIANE's text also used women's testimonials gathered through a support list on episiotomy created by AFAR's members. It sought to reframe the problem, moving away from the "prevention" of episiotomy towards discussion of perineal lacerations. This "semantic shift", as it was described in the text, opened up other policy options. It led to further recommendations relating to women's consent, professional training and medical protocols for the "management of labour". Furthermore it generated a severe critique of the $30 \%$ rate of episiotomies stated as an objective by CNGOF which, according to the CIANE, was not based on rational arguments and was too "political" in its attempts not to upset professionals. 


\section{Reframing issues: the post-partum haemorrhage case}

The issue of post-partum haemorrhage has been a focus of childbirth policies for 20 years, since it appears to be the major cause of avoidable maternal death. Compared to other European countries, France has a high maternal mortality rate and is the only country where haemorrhage is the first cause of death: thus the CNGOF prepared guidelines on the topic in 2004. The CIANE representative invited to assess these guidelines argued that they dealt entirely with treatment and did not envision any prevention policy. He suggested the hypothesis, established through internal discussions, that current medical practices - and especially the frequent use of oxytocin during the second stage of labour - could be the origin of the high rate of haemorrhage. The CIANE subsequently endeavoured to find funds to commission the main research centre specialising in perinatal epidemiology to undertake a research project exploring this link. A first paper published in the BMJ Open in December 2011 (Belghiti et al., 2011) confirmed this hypothesis. The CIANE issued a press release in March 2012 calling for a change of practices and a revision of guidelines. It recently submitted a proposal in response to a call issued by the French Medicines Agency that intends to support projects from patient organisations on the good use of medicines. This proposal would develop a series of actions in order to improve women's information on oxytocin, its use and associated risks.

This example shows the progressive specification of CIANE's policy, starting from the evaluation of guidelines, moving through involvement in research and finally reorienting action towards users' information. A similar pattern can be observed in the case of prenatal screening, where the CIANE supported the elaboration of guidelines which resulted in a drastic change in policy at the national level. The CIANE also supported the efforts of a French group of researchers trying to develop a non-invasive diagnostic technique and 
recently organised a training session for volunteers willing to answer women confronted with prenatal screening and seeking information, help and support on public internet forums.

The CIANE activities represent a loop from women's experience to scientific evidence and back to women. At each step, a translation is necessary in which "matters of fact give way to their complicated entanglements and become matters of concern" (Latour, 2005: 31). All elements - from women's desires to medical practices and scientific knowledge - are reframed through this process; their articulation is put centre stage and thus defines an arena where concerned parties - professionals, administrations and users - are convened.

International authoritative evidence as a source and a resource for the Portuguese childbirth movement

The childbirth movement in Portugal is a very recent one. Humpar, an association for the humanisation of childbirth, was founded in 2006 by a group of people involved in an organisation of doulas. The Doulas of Portugal Association (DPA) has been formed in 2005 on the initiative of two women who went to London in 2004 for training with Michel Odent, a French obstetrician and Liliana Hammers, a doula. Doulas support women during their pregnancy and childbirth: they appeared in the US in a context very similar to the current Portuguese one, i.e. where childbirth was taking place in a highly medicalised environment and where the profession of midwife has almost disappeared. So, from its inception, the Portuguese childbirth movement borrowed its mode of expression and action from foreign activities.

Humpar is part of an informal network of organisations which, apart from DPA, comprises Bionascimento, an organisation also founded by DPA members that provides services to 
doulas and midwives, and Maternar, a self-help group founded by Humpar members. These organisations have developed actions along two main related lines:

- the promotion of a childbirth model that would recognise both the physiological and familial character of the event, meaning a significant decrease in medical interventions and a more respectful attitude of health professionals and institutions towards parents;

- advocating for change in the Portuguese legal framework that defines childbirth as a medical event to be carried out in duly authorised medical establishments, with no recognition of midwifery as a profession.

In all their actions, these organisations have drawn extensively on a web of international references including institutions, other activist organisations, prominent figures and scientific literature or international recommendations.

WHO recommendations are cited in HUMPAR's charter as a reference for the improvement of maternity services and figure prominently on the Bionascimento website. They stand as a mandatory reference to which doulas must adhere and as the basis for the expression of public concern over caesarean section rates in the country. European Legislation and "other European countries" are cited as well as sources of inspiration for changing childbirth in Portugal. The websites of Humpar, Doulas of Portugal and Bionascimiento provide links to those of Brasilian, French, Spanish, British and International organisations. Some of these links correspond to actual contacts made through Portuguese participation in international meetings, such as a yearly doulas' meeting in Paris or the meeting of the Coalition for the Improvement of Maternity Services, an international organisation gathering individuals and national organisations, based in the USA. A number of prominent figures appear in all the websites either via quotations (Kofi Annan in the Homepage of the DPA website) or papers, some of them translated into Portuguese, authored by figures such as Michel Odent, Ricardo 
Jones (a Brasilian obstetrician), Laura Gutman (an Argentine writer on maternity), Suzanne Arms (an American activist) or Marsden Wagner (an American perinatologist who has headed the Women's and Children's Health in the WHO for 15 years and has reflected upon the use of technology in birth (1994)). References to scientific papers or international recommendations appear on the websites but mostly in official documents such as the " 10 Steps of Viana" and the "Right to normal birth consensus", which constitute the most visible achievements of the childbirth movement in Portugal.

The '10 Steps of Viana' were the outcome of a conference held in 2009 in northern Portugal involving a heterogeneous group of people associated with childbirth such as mothers, obstetricians, general practitioners, nurses, maternal health professionals, psychologists, journalists, consumer groups, doulas, teaching staff of medical and nursing schools and Humpar representatives. The aim of this meeting was to define 10 basic principles in order to improve childbirth in public hospitals. The document stating these ten principles was then presented to a general public and is available online for subscriptions. The organisations are currently working to disseminate it in maternal services and more widely.

The Portuguese consensus document, entitled "The Right to Normal Birth - A shared vision" was proposed by a group of obstetric and maternal health nurses and was intended as a formal recommendation to the Ministry of Health on the procedures taking place in public and private maternal care and childbirth services. This document draws on the same literature base as the 10 steps of Viana, namely 13 references mostly from the Cochrane Database Systematic Reviews, plus a number of academic papers and publications from international organisations such as the WHO, ICM (International Confederation of Midwives) and FIGO (International Federation of Gynecology and Obstetrics). Moreover, it mentions no less than 7 documents (out of 31) related to the elaboration of the British normal birth consensus statement discussed previously. 


\section{Setting up the Portuguese "matters of concern"}

Referral to this international literature in documents addressing the general public, professionals and political and governmental authorities, constitutes a key strategy of legitimation. The mobilisation of international frameworks for analysis and action has played a central role in constructing a program for engaging diverse publics in childbirth-related issues. The "humanisation" vocabulary borrowed from Brazilian birth movements and associated by Humpar's president with the French notion of "respectful birth", for example, puts the idea of empowering women on the agenda, emphasising that women are capable of making choices (although this in turn raises the question of which choices are possible within the current organisation of care related to childbirth).

The "normal birth" agenda, associated with the British example, appears in Portugal to be directed towards health authorities and professionals, providing guidelines for the establishment of a set of rules for practice and the allocation of competences and responsibilities to different kinds of professionals. It emerged in response to a policy-making initiative by the General Health Directorate who was interested in the elaboration of a consensus document. This Portuguese consensus document differs from the British one on significant points. Whilst the British document was the outcome of a long process which gave it its operative character - discernible in its title "Making normal birth a reality" - the Portuguese one may be regarded as a starting point of such a process. Firstly, it was negotiated expeditiously by organisations and individuals without a mandate from their members but rather in response to pressure from the General Health Directorate. As a result, the professional organisation of gynecologists and obstetricians has not yet signed the text despite its being available on a governemental website devoted to the National Health Plan 2012-2016. Secondly, the statistical apparatus that would make the consensus document operative is still only partially built: at one point Humpar sought collaboration from a 
research centre to collect data on maternal and infant perinatal mortality. Thirdly, the legal situation in Portugal is very different to the UK: midwifery has no official status in Portugal and homebirth is illegal. The title of the Portuguese document "The Right to Normal Birth" is evokes this situation and echoes the legal amendment initiative promoted by Humpar, the aim of which is to change the current definition of childbirth as a medical act. The weight given to this legal initiative by the organisation is linked to the presence in Humpar's governing body of three lawyers who are working on a bill redefining delivery as a natural event and not a medical act. The bill, if is passed by Parliament, is expected to have major implications, not only for the redefinition of childbirth, allowing it to be attended by people other than medical professionals, but also for the overall reorganisation of obstetric services across the National Health Service. In a similar vein, "The Right to Normal Birth" document adds interesting categories to that of "normal birth": natural birth, whose spontaneous beginning and progression culminates in birth with no intervention, which can be either assisted or not assisted by a health professional. This distinction, which legitimises a non-interventionist stance, performs two things: first, it a generates what is regarded by many as a threat - the expansion of non-assisted births - and the response to that threat - the recognition of a special body of professionals (midwives and/or obstetrical nurses) dedicated to this noninterventionist approach to birth.

The mobilisation by the Portuguese childbirth movement of foreign references is a powerful device to promote change: offering readily available strategies for action that can be adapted to the national situation. The articulation of local specificities to general frameworks is thus achieved in a quite different way than in the Irish case discussed above. 


\section{Discussion}

Although "evidential work" is at the core of each organisations' activities, the types of evidence in play and the articulations between knowledge activities and activism are quite different. How can we understand and make sense of these differences?

Our analysis suggests that the organisations' differing engagements with evidential work result from the dynamic interaction between the organisations' current characteristics, their histories and accumulated competencies and factors external to the organisations themselves. The French 2002 Act that imposed users' representatives in all health institutions, for example, created opportunities for health groups seeking to further their causes: CIANE strategically utilised this opportunity to be involved in elaborating guidelines for practice which appeared to them as the action most likely to lead to a transformation of care. In contrast, in Ireland, where no definitive statutory mechanism for consulting maternity service consumers (or their representatives) exists, surveys provided a mechanism to document women's concerns and raise them in a public way. Their use by AIMSI reflects a response to the prevailing health governance situation; the deployment of resources available to the organisation in the form of members' competence in designing surveys; the availability of the internet as a dissemination tool and the overarching commitment of the organisation to being consumer led.

"Explaining" the organisations' evidential work is thus equivalent to unfolding a web of relations: specific knowledge activities are born out of heterogeneous elements; individuals, resources, accumulated history of the organisation, institutional and legal frameworks, key events and even particular international connections and resources, among which we can mention the participation of AIMS UK, CIANE and Humpar in a European network of childbirth organisations or the links of AIMSI with AIMS UK. EBM, as source of an 
international standardisation of practices, sometimes stimulates a "synchronisation" of concerns among childbirth groups: for instance, the publication in 2010 of a meta analysis in the American journal of Obstetrics and Gynecology (Wax, 2010) stating that the risk of perinatal death was tripled in homebirth compared to hospital births immediately provoked an intense and worldwide circulation of comments and counter-argumentations, involving amongst others the NCT, BirthChoiceUK, the CIANE, AIMS UK, the US Coalition for the Improvement of Maternity Services and other midwives groups. The dynamics between the specificities of local organisations and contexts together with the synchronising impact of international factors account for the simultaneous deployment of original modes of action interlaced with common features.

A second factor that seems pertinent to understanding the knowledge activities of the organisations relates to the "utilisation" of evidence. While the organisations we studied organise key elements of their activities and strategies around the collection and production of evidence, they are not moving towards evidence-based policy as reflected in the general meaning of that term, i.e. policies that are based on "objective evidence" (Sanderson, 2002). Childbirth organisations use evidence in a different way: they do not seek to root policymaking in "science", as would be the case in a technocratic or purist understanding of evidence-based policy making. They mobilise evidence to constitute and highlight "matters of concern" and not solely to establish indisputable "matters of fact". In the latter case, the role of evidence is to close the discussion by defining an empirically verifiable "reality"; in the former case, evidence is intended to open or re-open discussion by including issues and actors that were previously excluded (Latour, 2005). In collecting and publishing data on their occurance, BirthChoiceUK brought particular medical interventions into a new realm of debate outside the confines of hospitals or the dusty cupboards of the Department of Health. In the Irish context the inadequacy of consent procedures in Irish maternity units and the lack 
of information on maternity related procedures were encapsulated in individual experience, while in France the link between medical practices and adverse effects such as post-partum haemorrhage which had not been publicly or scientifically articulated was highlighted.

Yet, the organisations we studied also deployed 'mainstream' evidence-based medicine to strategically oppose the routine use of certain interventions. But it is not the case that childbirth movements have moved from a reference to "Nature" in their earlier days to a reference to EBM as a guiding principle of obstetrical practices. They also developed critiques of EBM, pointing to its lack of rigour in some cases (Gyte, 2011) and to the inadequacy of EBM standards of proof in many issues (Gyte, 2010; Bel, 2004; Loup, 2005). Our analysis thus suggests that while scientific evidence was one genre of evidence mobilised by the organisations, their evidence work was more varied and expansive and was characterised by the production and articulation of different forms of evidence, called upon by Hausman (2005). Indeed in many instances, their work consists of unpacking the assumptions supporting practice and of articulating a new form of knowing in which local experiential knowledge provided by service users is translated through or connected with, international, credentialised, evidence-based medicine. A case in point is the way in which the CIANE combined various forms of knowledge in its critique of the guidelines on episiotomy. Through this articulation work, the clear-cut distinction between experiential expertise and scientific expertise that appears in the literature on lay expertise is partly erased. This reflects the reality that women's experiences of maternity care cannot be separated from medicine, not only because the experience of childbirth as well as illness experience (Anglin, 1997) involves the intervention of medical procedures but also because women's bodily experience is informed by medical knowledge and technologies (Akrich \& Pasveer, 2004; Akrich, 2010). Consequently the lobbying efforts deployed by childbirth organisations converge with those directed towards women's support and information. We saw for example how the collection 
of statistics on British obstetrical practices simultaneously served to define "normal birth" and to generate a mechanism whereby information on hospital specific practices was made available to women. Similarly the Irish surveys, which were designed to inform the organisation's agenda and shape its campaign work, also underpinned the design of its Healthy Birth Directory for the West of Ireland (2011), an information resource for women.

Finally, because knowledge activities perform a tentative definition of the issues at stake, the actors to be represented, the causal relations and thus an attribution of responsibilities in all our case studies, they contribute to the definition and redefinition of the organisations' strategies and causes. The work on statistics in the UK case opened up a space for negotiation and action and resulted in a definition of "normal birth" that constitutes an evolution of the organisation's previous position; the Irish surveys contributed to the definition of a programme of actions for AIMSI and at the same time provided them with arguments and legitimacy that strengthened their capacities for action; the production of a critical review on post partum haemorrhage led the CIANE to invest in research, the results of which opened a new field for action; and the mobilisation of foreign repertoires by Portuguese organisations prompted them to delineate the Portuguese situation as regards childbirth care.

It would thus appear that the momentum generated through knowledge activities can potentially re-orient and indeed de-stabilise the organisations. We have observed that in the self descriptions of the organisations we studied varied concepts such as "choice", "normal birth" and "evidence-based care" underpin key objectives. However these objectives do not always fit together and sometimes refer to different principles of justification, causing the organisations to live within a regime of permanent compromise (Boltanski \& Thévenot, 2006). Although intrinsically linked to the organisations' constitution, these principles may oppose one another when put under strain by certain actions. For example, whereas in the first CIANE mission statement increasing choice was equated with developing care practices 
devoted to a physiological approach to birth, the reference to physiology disappeared from the 2011 leaflet. The CIANE did not abandon the cause of free-standing birth centres, but its involvement in the elaboration of guidelines pushed aside the notion of physiology which did not fit well in a framework dominated by EBM. The reference to EBM itself conflicted with the idea of choice, leading to tensions between promoters of breastfeeding who wanted it to be privileged because of its scientifically demonstrated advantages (still coupled to a reference to nature as being the prominent normative source) and other CIANE members more sensitive to women's right to choose. Similarly, in the UK, the "normal birth" consensus affirmed divisions in the birth activism field, as the way normal birth was set up as a quality measure through the implementation of indicators based on statistics conflicted with the vision of organisations such as BirthTrauma or electivecaesarian.com. In all these examples, we see how the compromises underlying the existence of these organisations can be put under stress, transformed or displaced by the organisations' knowledge activities. This regime of compromise is, we argue, reinforced by the knowledge orientation of childbirth organisations which opens up spaces for public discussion around "matters of concern", challenging the application of unique normative principles. It does not mean that all options are equivalent, it implies rather that each one is confronted with its own complexity.

\section{Conclusion}

The childbirth organisations we studied do similar kinds of things. Firstly, a large part of their activities is devoted to what we call evidential work, i.e. the collection, the production and the mobilisation of various forms of knowledge and their articulation in sound argumentation. Secondly, this evidential work results in the emergence of "matters of concern" to be discussed between all parties involved: in contrast to the movements in the 70 s that have been more or less portrayed as new social movements (Buechler, 1995; Pichardo, 1997), the 
childbirth organisations clearly adopt a reformist perspective and do not directly oppose obstetricians and medicalisation; investing in medical science, they place themselves within the obstetrical collective that they seek to transform. Thirdly, knowledge and evidence play a pivotal role in relationships between users and professionals at a collective level: it is the language through which a negotiation is set up between the organisation, professionals and health policy makers. This is also true at an individual level: organisations consider that giving women access to knowledge and evidence can help to open up spaces for self determination and for meaningful discussion with professionals. Fourthly, the objectives and missions of the organisations are partly shaped and re-shaped through this evidential work, in contrast to previous descriptions of childbirth organisations that insisted on their strong commitment to a specific cause structuring their form of activism. Moreover, it appears that evidential work sustains a kind of ideological pluralism within the organisations. So, the "matters of concern" emerging from the organisations' activities affect not only the relationships between the organisations and their interlocutors but the organisations themselves: this clearly differentiates these organisations from Embodied Health Movements (Brown, 2004) in which the mobilisation of science is oriented towards the reinforcement of a politicised collective identity.

Thus, our description highlights the originality of contemporary childbirth movements, both in comparison with descriptions of health movements in general and with previous descriptions of childbirth movements. The perspective we adopted, our focus on their practices, may account for these differences. It might also be the case that childbirth activism has progressively transformed over years. In any case, by producing evidence that publicly convoke unexpected entities, these movements participate in the widening of "technical democracy" (Callon et al, 2004) through two main processes: (i) re-opening the list of issues that should be taken into consideration in medical practices beyond those brought in by 
medical science, and (ii) questioning the assumptions underlying the choice of factors to be considered for the production of scientific facts.

\section{Acknowledgements}

This article is based on a European research project called EPOKS (European Patients' Organizations in Knowledge Society), supported by the European Commission FP7. We warmly thank all patients' organizations which participated to our surveys, ans especially their leaders who agreed to be interviewed and let us participate as observers to different meetings. Etaoine Howlett, postdoctoral researcher at University College Cork, conducted interviews and undertook a range of research tasks relating to the Irish element of the study. The UK case study was undertaken by Celia Roberts, Imogen Tyler and Candice Satchwell. Interviews cited here were conducted by Candice Satchwell.

\section{References}

AIMS Ireland, Members eNewsletter (2007), 2, 2.

Akrich, M. (2010) From communities of Practice to Epistemic Communities: Health Mobilizations on the Internet, Sociological Research Online, 15, 2.

Akrich, M. and Pasveer, B. (2004) Embodiment and Disembodiment in Childbirth Narratives, Body \& Society. Special Issue on Bodies on Trial., 10, 63-84.

Allsop, J., Jones, K. and Baggott, R. (2004) Health consumer groups in the UK: a new social movement?, Sociology of Health and Illness, 26(6), 737-756.

Anglin, M. (1997) Working from the inside out: implications of breast cancer activism for biomedical policies and practices, Social Science \& Medicine, 44(9), 1403-1415. 
Barbot, J. (2006) how to build and "active" patient? The work of AIDS associations in France. Social Science \& Medicine, 62, 538-551.

Beckett, K. (2005) Choosing Cesarean: Feminism and the Politics of Childbirth in the United States. Feminist Theory 6(3), 251-75

Beckett, K. and Hoffman, B. (2005) Challenging Medicine: Law, Resistance, and the Cultural Politics of Childbirth, Law \& Society Review, 39, 125-170.

Beech, B. L. (1997) Normal birth: Does it exist? AIMS Journal 9(2), 4 - 8

Beech, B.L. (2008) Making Normal Birth a Reality, AIMS Journal, 20(4), http://www.aims.org.uk/Journal/Vol20No4/makingNormalBirthAReality.htm, accessed on 12 April 2012.

Beech, B. L. (2011) Challenging the Medicalisation of Birth, AIMS Journal, 23(2), http://aims.org.uk/Journal/Vol23No2/challengingmedicalisation.htm, accessed on 12 April 2012.

Bel, B. (2004) Protocoles obstétricaux et données probantes des études scientifiques: une panacée ? Journées annuelles de santé publique. Conférence annuelle de l'Association pour la santé publique du Québec, Montréal, Québec, Canada.

Belghiti, J., Kayem, G., Dupont, C., Rudigoz, R.-C., Bouvier-Colle, M.-H. and DeneuxTharaux, C. (2011) Oxytocin during labour and risk of severe postpartum haemorrhage: a population-based, cohort nested case-control study, BMJ Open, 1:e000514

Boltanski, L. and Thévenot, L. (2006) On Justification: Economies of Worth, Princeton and Oxford: Princeton University Press. 
Buechler, S.M. (1995) New social movement theories, Sociological Quarterly, 36 (3), 441464.

Callon, M., Lascoumes, P. and Barthe, Y. (2001) Agir dans un monde incertain. Essai sur la démocratie technique, Paris: Le Seuil. Published in English in 2011: Acting in an Uncertain World: An Essay on Technical Democracy, Cambridge Mass.: MIT Press.

Collins, H.M. and Evans, R. (2002) The Third Wave of Science Studies: Studies of Expertise and Experience, Social Studies of Science, 32(2), 235-296.

Crossley, M.L. (2007) Childbirth, Complications and the Illusion of 'Choice': A Case Study, Feminism Psychology, 17(4), 543-563.

Darra, S. (2009) 'Normal', 'natural', 'good' or 'good-enough' birth: examining the concepts, Nursing Inquiry, 16(4), 297-305.

Dick-Read, G. (1956) The Natural Childbirth Primer. New York: Harper.

Dodwell, M. \& Newburn, M. (2010) Normal birth as a measure of the quality of care: evidence on safety, effectiveness and women's experiences, London: Natural Childbirth Trust.

Donovan, S. (2006) Inescapable burden of choice? The impact of a culture of prenatal screening on women's experiences of pregnancy, Health Sociology Review, 15(4), 397-405.

Downe S., McCormick and Beech, B.L. (2001) Labour interventions associated with normal birth, British Journal of Midwifery, 9(10), 602-606.

Downe S.(2004) Normal childbirth:Evidence and debate, London: Churchill Livingstone. 
Epstein, S. (1996) Impure Science: AIDS, Activism, and the Politics of Knowledge, Berkley: University of California Press.

Epstein, S. (2008) Patient Groups and Health Movements, In Hackett, E.J., Amsterdamska, O., Lynch, M. and Wajcman, J. (eds) The Handbook of Science and Technology Studies (3rd edition), Massachusetts: MIT Press, 499-538.

Gillis, \& Munford, R. (2004) Genealogies and generations: the politics and praxis of third wave feminism. Women's History Review, 13(2), 165-182.

Goer, H. (2003) "Spin Doctoring" the Research, Birth, 30(2), 124-129.

Goer, H. (2004) Humanizing birth: a global grassroots movement. Birth 31(4), 308-314.

Graham, I. D. (1998)Processes of Change in Obstetrics: A Cross-National Case-Study of Episiotomy. Health, 2( 4), 403-33.

Gyte, G., Dodwell, M.J., \& Macfarlane, A.J. (2011) Home birth metaanalysis: does it meet AJOG's reporting requirements?, American Journal of Obstetrics and Gynecology, 204 (4) e15.

Gyte, G., Newburn, M. \& Macfarlane, A. (2010) Critique of a meta-analysis by Wax and colleagues which has claimed that there is a three-times greater risk of neonatal death among babies without congenital anomalies planned to be born at home, July 7, 2010. http://www.scribd.com/doc/34065092/Critique-of-a-meta-analysis-by-Wax. Accessed on 30 March 2012.

Halfon, S. (2010) Encountering birth: negotiating expertise, networks, and my STS self. Science as culture, 19(1), 61-77. 
Hausman, B.L. (2005) Risky Business: Framing Childbirth in Hospital Settings, Journal of Medical Humanities, V26, 1, 23-38.

Hensley Owens, K. (2009) Confronting Rhetorical Disability: A critical analysis of women's birth plans. Written Communication 26(3), 247-272.

Hunter, B. (2007) The all Wales clinical pathway for normal labour: What are the experiences of midwives, doctors, managers and mothers? Final project report. Swansea: School of Health Science, Swansea University.

Jasanoff, S. (2005) Designs on Nature: Science and Democracy in Europe and the United States. Princeton: Princeton University Press.

Johanson, R. and Newburn, M. (2001) Promoting normality in childbirth, BMJ, 323(7322), $1142-1143$.

Johanson, R., Newburn, M. and Macfarlane, A. (2002) Has the medicalisation of childbirth gone too far?, BMJ, 324(7342), 892-895.

Kitzinger, S. (1975) Some mothers' experiences of induced labour, London: National Childbirth Trust.

Kitzinger, S. (1987) Some Women's Experiences of Epidurals: a descriptive study, London: Natural Childbirth Trust.

Kitzinger, S., Walters, R. (1981) Some women's experiences of episiotomy, London: Natural Childbirth Trust. 
Latour, B. (2005) From Realpolitik to Dingpolitik or How to Make Things Public, In Latour, B. and Weibel, P. (eds) Making Things Public. Atmospheres of Democracy, Karlsruhe, Cambridge (MA): ZKM, MIT Press, 14-31.

Loup, C. (2005), Accouchement à domicile, note préparée pour le groupe de travail de la HAS sur les grossesses physiologiques.

Maternity Care Working Party (2007) Making Normal Birth a Reality: Consensus statement from the Maternity Care Working Party, www.mcwp.org.uk

Murphy-Lawless, J. (1998) Reading Birth and Death. A History of Obstetric Thinking, Bloomington \& Indianapolis: Indiana University Press.

National Institute for Health and Clinical Excellence (NICE). (2007) Intrapartum care: management and delivery of care to women in labour. London: RCOG Press.

Phan, E. (2010) La remise en cause de pratiques médicales professionnelles de la part des usagers de la périnatalité. Quelle légitimité?, Revue de médecine périnatale, 2(1), 48-53.

Pichardo, N.A. (1997) New Social Movements: A Critical Review, Annual Review of Sociology, 23 (1), 411-430.

Rabeharisoa, V. and Callon, M. (2002) The involvements of patients' associations in research, International Social Science Journal, 171, 57-65.

Rabeharisoa, V. (2003) The struggle against neuromuscular diseases in France and the emergence of the "partnership model" of patient organisation, Social Science \& Medicine, 57, 2127-2136. 
Reiger, K. (1999) Birthing in the Postmodern Moment: Struggles over Defining Maternity Care Needs, Australian Feminist Studies, 14, 387-404.

Reiger, K. (2000) Reconceiving citizenship: the challenge of mothers as political activists. Feminist Theory, 1 (3), 309-327.

Reiger, K. \& Dempsey, R. (2006) Performing birth in a culture of fear: an embodied crisis of late modernity. Heath Sociology Review, 15(4), 364-373.

Samerski, S. (2009) Genetic counselling and the fiction of choice: taught self-determination as a new technique of social engineering. Signs: Journal of Women in Culture and Society, 34(4), 735-761.

Sanderson, I. (2002) Evaluation, Policy Learning and Evidence-Based Policy Making, Public Administration, $80(1), 1-22$.

Shaw, R. (2007) I. It's Your Body, Your Baby, Your Birth': Planning and Achieving a Home Birth, Feminism Psychology, 17(4), 565-570.

Thoma, P. (2009) Buying up baby. Feminist Media Studies 9(4), 409-425.

Tong, R. (2007) feminist through in transition: never a dull moment. The social Science Journal 44(1), 23-39.

Wagner, M. (1994) Pursuing the Birth Machine: The Search for Appropriate Birth Technology. New South Wales, Australia: Ace Graphics.

Wax, J.R., Lucas, F.L., Lamont, M. et al. (2010) Maternal and newborn outcomes in planned home birth vs planned hospital births: a metaanalysis. American Journal of Obstetrics and Gynecology, 203 (243) e1-8. 
Weiner, L. Y. (1994) Reconstructing Motherhood: The La Leche League in Postwar America. The Journal of American History, 80(4),1357-81.

Williamson, C. (2008) The patient movement as an emancipation movement, Health Expectations, 11, 102-112.

World Health Organisation. (1996) Safe motherhood. Care in normal birth: a practical guide. Geneva: World Health Organisation.

World Health Organisation (1997) Care in Normal Birth: A Practical Guide. Geneva: World Health Organisation.

Zwelling, E. (2002) Activist for Change: An Interview with Suzanne Arms, Journal of Perinatal Education, 11(4), 11-24. 